УДК 316.334:796

DOI 10.52575/2712-746X-2021-46-4-652-661

\title{
Генезис спорта: обзор основных теорий
}

\author{
Лукащук В.И. \\ Академия маркетинга и социально-информационных технологий - ИМСИТ, \\ Россия, 350010, г. Краснодар, ул. Зиповская, 5 \\ E-mail: luka81@list.ru
}

\begin{abstract}
Аннотация. Рассмотрены основные теоретические подходы к анализу генезиса спорта как социального феномена. Показано, что современные формы существования спортивных практик связаны с эволюцией социально-экономических отношений, складывающихся на том или ином этапе исторического развития общества. Появление в социальной среде новых форм спортивных практик обусловлено формированием специфических общественно значимых потребностей. Проанализированы различные направления эволюции спорта: социально-экономический, религиозный, игровой, культурный, воспитательный, образовательный, технологический. Отмечено, что заметное место при анализе социального аспекта развития спорта занимают работы, в которых рассматриваются детерминанты становления и функционирования его как зрелища. Показано, что в современных условиях зрелищный спорт становится формой профессионально организованного взаимодействия, приобретая черты искусства как специфической формы общественного мнения. При этом изменяется его социальный статус и социальные функции. Согласно законам шоу-бизнеса, современный спорт стремится максимально расширить свою потенциальную аудиторию, диверсифицировать свою структуру, находя все новые и новые виды соревнований.
\end{abstract}

Ключевые слова: спорт, спорт как социальный феномен, социология спорта, трансформация спорта, спортивные практики, индустрия спорта.

Для цитирования: Лукащук В.И. 2021. Генезис спорта: обзор основных теорий. NOMOTHETIKA: Философия. Социология. Право, 46(4): 652-661. DOI: 10.52575/2712-746X-202146-4-652-661

\section{Sport Genesis: Review of the Main Theories}

\author{
Vitalii I. Lukashchuk \\ Academy of Marketing and Social Information Technologies, \\ 5 Zipovskaya St, Krasnodar 350010, Russian Federation \\ E-mail: luka81@list.ru
}

\begin{abstract}
The main theories of sport development as a social phenomenon are considered. Today, sport is under the influence of globalization processes, which have repeatedly strengthened the role and importance of sport as a global phenomenon. It is shown that the modern forms of sport existence are related to the evolution of socio-economic relations that develop at a certain stage of the historical progress of society. The emergence of new forms of sport practices in the social environment is due to the formation of specific socially significant needs. The author analyzes various directions of sport evolution: socio-economic, religious, gaming, cultural, educational, and technological. It is noted that a significant place in the analysis of the social aspect of sport development of is occupied by works that consider the determinants of its formation and functioning as a spectacle. It is shown that in modern conditions, spectator sport becomes a form of professionally organized interaction, acquiring the features of art as a specific form of public opinion. At the same time, its social status and social functions change. According to the laws of show business, modern sport is trying to maximize its potential audience, diversify its structure, finding more and more new types of competitions. The article notes that in the context of globalization, the values of traditional sports are being transformed, which leads to
\end{abstract}


changes not only in all its components, but also in the moral and spiritual life of not only athletes, but also, to a greater extent, spectators.

Keywords: sport, sport as a social phenomenon, sociology of sport, sport genesis, transformation of sport, sport practices, sport industry.

For citation: Lukashchuk V. I. 2021. Sport Genesis: Review of the Main Theories. NOMOTHETIKA: Philosophy. Sociology. Law, 46 (4): 652-661 (in Russian). DOI: 10.52575/2712-746X-2021-46-4-652-661

\section{Введение}

На протяжении нескольких десятилетий наблюдается устойчивая тенденция усиления влияния спорта на общественную жизнь и сознание людей. Современный спорт охватывает все слои социума, влияя на основные сферы жизнедеятельности общества: экономику, политику, образование, медицину, фармакологию и др., влияет на национальные отношения и этические ценности; формирует модные тренды образа жизни людей. Сегодня спорт превратился в своего рода индустрию, в которую входят спортивные, оздоровительные, технические, управленческие, образовательные и научные организации, а также спортивная промышленность, средства массовой информации, производство спортивной одежды и оборудования и тому подобное. Эта новая реальность оказалась практически незамеченной социологами, доказательством чего является то, что глубоких монографических работ по поводу выяснения причин такой трансформации, закономерностей функционирования и особенностей управления индустрией спорта в отечественной социологии практически нет.

Некоторые ученые объясняют это тем, что «социолог спорта не интересен социологам, потому что они не интересуются спортом. А спортсмены не интересуются социологией» [Эдельман и др., 2017, с. 282]. Тем не менее в современной отечественной социологической литературе о спорте стали все чаще появляться работы, авторы которых акцентируют внимание на необходимости развития социологии спорта в нашей стране [Лукащук, 2020; Синютин и др., 2020; Быховская, Мильштейн, 2017; Сироткина, 2017]. Особо следует подчеркнуть, что в российской социологии спорта основной анализ делается не столько на вопросах социологического характера, сколько на проблемах самого спорта, развития его отдельных видов; работы преимущественно носят эмпирический характер, что не совпадает с мнением ведущих российских социологов, считающих, что «эмпирическая работа социологов от начала до конца должна сопровождаться работой теоретической» [Романовский, 2019, с. 152]. Такое положение сегодняшнего состояния социологии спорта требует системных исследований в данной области.

Первым этапом такого исследования мне видится социологический анализ генезиса спорта как социокультурного феномена, что позволяет, опираясь на изучение разных теоретических концепций становления и развития спорта, понять природу данного явления, внутреннюю логику его развития, определить тенденции его дальнейшей эволюции.

\section{Генезис спорта как объект социологического исследования}

Генезису спорта как социального явления посвящена работа Н. Элиаса [2006], в которой автор прежде всего уточняет, что спорт в широком смысле содержит все соревнования и физические упражнения, которые встречаются в любых обществах; в узком смысле понятие спорт относится только к определенному типу игр, который возник в Англии и оттуда распространялся в другие государства. При этом исследователь предлагает изучать трансформацию форм досуга в спортивные соревнования во взаимосвязи с процессами 
становления национальных государств, т.е. как связаны между собой тенденции преобразования общества в современный тип. Историю спорта Н. Элиас исследует посредством сравнительного анализа спортивных игр Древней Греции и современности. При этом автор отмечает, что в любом обществе существует тесная взаимосвязь между всеми жизненными проявлениями, поэтому исследователь должен принять во внимание целостную внутреннюю систему ценностей этого общества.

Цивилизационный подход Н. Элиаса позволяет определить исторический релятивизм спортивных форм, зависимость целей проведения соревнований, правил их проведения и стандартов их оценки от общей социокультурной ситуации, ценностного основания конкретного социума.

По мнению П. Бурдье, «история спортивных занятий может быть только структурной историей» [Бурдье, 1994, с. 260]. Предметом истории спорта социолог считает такие преобразования структуры, которые могут быть понятыми только на основании знания о том, чем именно была эта структура в конкретный момент времени. Изменения таким образом приобретают познавательный смысл исключительно в мире первобытного знания структуры. Кроме того, важно помнить, что пространство спорта не существует само по себе: оно замкнуто в пространство практик и потребления, которые, в свою очередь, структурированы и конституированы в систему. Поэтому спортивные практики могут восприниматься как модальность между предложением, рассматриваемым как совокупность моделей практик, и спросом как продуктом индивидуального габитуса [Бурдье, 1994, с. 265].

Многие исследователи для объяснения социальной сущности спорта обращаются к анализу Олимпийских игр Древней Греции, гладиаторских боев Древнего Рима или рыцарских турниров средневековой Европы [Кун, 1982; Столяров, 2005]. Л. Кун, характеризуя общественно-экономические условия Древней Греции, выделил факторы, которые сказались на эволюции всех направлений спорта, основными из которых являются: а) дальнейшее развитие процесса разделения труда; б) расслоение общества по имущественному признаку; в) интенсивное ведение войн; г) формирование государственности и дальнейшее развитие языческой религии; д) появление рабства. Исследователь подчеркивает, что активное ведение войн определило основную форму и содержание воспитательного направления в развитии спорта. Системы воспитания молодежи сформировались в Древней Греции и Древнем Риме (как наиболее показательные из существовавших в то время), несмотря на имеющиеся различия в организации, ориентировались в первую очередь на подготовку физически сильных, закаленных воинов, поскольку успех в бою во многом зависел от их физической подготовки [Кун, 1982]. Это стало важнейшей тенденцией в развитии спорта, потому что сформировало систему воспитания, в которую обязательно включались физические упражнения, используемые в ходе боевых действий. Таким образом, данное направление в развитии спорта приобрело военно-физическую направленность, сохранившуюся и на следующем этапе общественного развития.

Д.Г. Кайл [Kyle, 2014], объясняя многообразие и противоречия современного спорта, ищет его корни в первобытнообщинном обществе. Исследователь считает, что стимулирующими мотивами развития спорта было, во-первых, решение личностных конфликтов путем соревнования в выносливости, ловкости, силе. Аборигены начали использовать игры и соревнования как способ мирного противоборства в отличие от кровопролития. Обряды выбора вождя, завоевания невесты как мирное противоборство появились значительно раньше, чем подготовка к соревнованиям. Во-вторых, необходимость совершенствования ведущей трудовой деятельности - охоты - со временем привело к распространению соревнований по бегу, стрельбе из лука и тому подобное. 


\section{Религиозное направление в развитии спорта}

Некоторые ученые выделяют религиозное направление в развитии спорта [Grano, 2017; Alpert, 2015]. Иногда само возникновение спорта связывают с религиозными ритуалами, важной частью которых были различного рода спортивные соревнования. Д. Грано [Grano, 2017] считает, что в современном обществе спорт сформировался как подобие религии с собственными ритуалами и обрядами, отличными от прежних форм массовых действий. По мнению автора, произошло это потому, что в XIX-XX веках произошло существенное ослабление институтов религии, а потребность в формах и действиях, выполняемых ими, осталась, поэтому спорт принял на себя данные функции и создал новый культ со своими поклонниками и сторонниками, кумирами и служителями. Он сформировал собственные ритуалы и обряды, отличные от прежних формы массовой действия.

Б. Джей [Jeu, 1992], указывая на ритуальное становление спортивных практик, акцентирует внимание на ценностно-эстетическом потенциале спорта, на особенностях его отражения в искусстве, рассматривает спорт как источник вдохновения для писателей, поэтов, художников. О. Групе [Grupe, 2000] также фокусирует взгляд на спорте как культурном феномене и отмечает, что с ним связано множество культурных ценностей. Ученые сходятся во мнении, что возникновение спортивных игр было обусловлено проведением главных религиозных праздников в честь богов. Это исторически обусловленная, главная социальная потребность на многие годы определила их общественную значимость и привела к их систематическому воспроизведению.

Рассматривая вопрос влияния религии на развитие спорта, Г. Люшен задается вопросом: можно ли современный спорт рассматривать как феномен протестантской культуры [Люшен, 1974]. В основе его рассуждений лежит идея М. Вебера о связи протестантской этики с духом капитализма [Вебер, 1990]. По М. Веберу, людей, придерживающихся протестантской веры, всегда отличает стремление к образованию, занятиям торговлей и промышленностью. Г. Люшен обращает внимание на то, что и в сфере спорта заметно преобладают ценности аскетизма и достижения цели. Веря в то, что успех - знак божественной благодати, протестанты делают культом достижение цели, и спорт предоставляет для этого большие возможности. Поэтому даже пуритане, которые обычно враждебно относились к праздному времяпрепровождению, одобряли занятия спортом как разновидность физической деятельности, которая укрепляет здоровье.

Анализируя влияние религии на развитие спорта в Древней Греции, ученые [Belsky, 2016; Goldblatt, 2016; Alpert R., 2015] отмечают, что в те времена доминирующее значение в обществе имела религия. Спортивные же соревнования, проводившиеся в рамках религиозных праздников, были лишь своеобразной формой ритуальных поклонений богам. Исходя из этого, подвергаются критике взгляды ученых, которые считают, что миротворческая функция Олимпийских игр была главной и с самого начала им принадлежала [Belsky, 2016; Лукащук, 2011b]. По мнению Г. Бельского [Belsky, 2016] войны прекращались не потому, что проводились Олимпийские игры, а прежде всего потому, что в это время происходили религиозные празднества, имеющие общегосударственное значение, потому что на них съезжались руководители всех греческих государств для заключения мирных договоров, налаживания торговых и культурных связей. Именно поэтому во время религиозных праздников прекращались войны, а в рамках культовых обрядов устраивались олимпийские агоны во славу богам.

\section{Значение игрового компонента в генезисе спорта}

Среди работ, освещающих значение игрового компонента в генезисе спорта, наиболее значимыми являются работы испанского ученого Х. Ортеги-и-Гассета и нидерландского культуролога Й. Хейзинги. 
По мнению Х. Ортеги-и-Гассета [1991], спорт возник под воздействием «свободной игры жизненных сил», которая порождает инстинктивное, избыточное, т.е. антиэкономическое усилие. Стремительное распространение современного спорта Х. Ортега-и-Гассет связывает с тем фактом, что в XIX в. приоритетом в обществе была работа, а в XX в. таковым становится игра с присущим ей карнавально-праздничным пониманием жизни. Еще одной причиной распространения различных спортивных практик ученый видит в утверждении философии бодицетризма, согласно которой одной из основных культурных установок является культ тела, его желания, потребности и инстинкты, то есть тело становится своего рода контролером души. По мнению ученого, спорт является фактором как духовного закрепощения личности, так и инфантилизации современной культуры. «За короткое время мы увидели, насколько поднялась на страницах газет волна спортивных игрищ, потопив почти все корабли серьезности... Торжество спорта означает победу юношеских ценностей над ценностями старости... Европа вступает в эпоху ребячества», - утверждает ученый [Ортега-и-Гассет, 1991, с. 257]. Безусловно, положения Х. Ортеги-и-Гассета о становлении и ценностях современного спорта являются дискуссионными, но все же с некоторыми из них можно согласиться.

Й. Хейзинга оспаривает спортивно-игровую теорию Х. Ортеги-и-Гассета и обращает внимание на тот факт, что, начиная с XIX века, к спортивным играм относятся все серьезнее, детализируются и становятся более строгими правила соревнований, растут результаты. Все это приводит к профессионализации спорта, постепенно вытесняя из него спонтанность, раскрепощенность и легкость, то есть игровой компонент. Для профессионального спортсмена спорт становится работой, а не игрой. Тем не менее Й. Хейзинга ставит спорт в современной социальной жизни на обочину истинного культурного процесса, поскольку он лишен прежней одухотворенности, оторван от духовной культуры общества и даже при поддержке государства не имеет органической связи со структурой общества, он выражает, скорее, инстинкты. «Несмотря на все свое значение для участников и зрителей, он остается бесплодной функцией, в которой давний игровой фактор по большей части уже успел отмереть» [Хейзинга, 1997, с. 223]. В данном контексте Й. Хейзинга снова оспаривает выводы Х. Ортеги-и-Гассета, необоснованно поставившего спорт выше культуры. Указывая на социальные функции спорта, Й. Хейзинга отмечает, что его значение как основной игровой формы современности постоянно увеличивается и связано со структурой социальной жизни общества. Именно потребностями общества объясняет он создание спортивных организаций.

Идеи Й. Хейзинги о том, что игра находится за пределами реального, дали основание его последователям сформулировать тезис о том, что игра, а вместе с ней спорт и физическое воспитание представляют возможность ухода, бегства от реальной жизни. Характерным для Й. Хейзинги является отождествление игры с порядком. При этом она выступает как важный социальный инструмент поддержания дисциплины в коллективе и обществе. Отождествление игры с ритуалом с одной стороны и порядком с другой представляет собой важное для социологической науки и практики спорта положение, поскольку оно дает основание рассматривать спорт и физическое воспитание как важные инструменты социального порядка и контроля. Значение исследования Й. Хейзинги для социологии спорта велико и в настоящее время. Теория Й. Хейзинги продолжает оказывать влияние на научное мировоззрение социологов спорта, досуга, рекреации, специалистов физического воспитания.

\section{Влияние национальных систем образования на развитие спорта}

На становление и функционирование современного спорта значительно повлияли процессы формирования национальных систем образования, в рамках которых создавались свои системы физического воспитания [Schwartz, 2021]. По мнению Р. Кречмара с 
соавторами [Kretchmar et al., 2017] развитию современных спортивных практик содействовали школы гуманизма, так называемые филантропины, которые возникли в XVIII веке в Германии. Педагогов-филантропистов И. Гутс-Мутса и Г. Фита по праву считают основателями немецкой системы гимнастики, дальнейшему развитию которой посвятил свои силы Ф. Ян и А. Шпис. С именем П. Линга связано становление национальной системы гимнастики Швеции, а чешский педагог М. Тырш известен как создатель сокольской гимнастической системы. Во второй половине XIX и начале XX веков формировались оригинальные системы физического воспитания во многих странах: во Франции система Ж. Демени, основанная на ведущем значении ритма и гармонии движений, на ритмичном чередовании расслабления и напряжения мышц; в Дании - система Н. Бук, которая представляла собой модернизированный вариант шведской гимнастики, в Великобритании - спортивно-игровой метод и другие. Они сыграли важную роль в привлечении широких слоев населения к ценностям спорта.

По мнению П. Крэйга [Craig, 2016], современные формы существования спортивных практик (физическое воспитание, спорт, физическая рекреация и т.д.) являются следствием их исторической эволюции, развитие этих форм неразрывно связано с трансформацией социально-экономических отношений, складывающихся на том или ином этапе исторического развития общества. Появление в социальной среде новых форм спортивных практик обусловлено формированием специфических общественно значимых потребностей.

\section{Роль научно-технических новаций в развитии современного спорта}

Некоторые ученые исследуют роль научно-технических новаций в развитии современного спорта [Лукащук, 2011a; Schmidt, 2020]. С.Л. Шмидт, например, считает, что научно-техническая революция обеспечила значительный рост потенциальных потребителей спортивных услуг, а В.И. Лукащук отмечает, что внедрение современных технологий меняет образ спорта, способствует развитию его новых видов, облегчает подготовку и восстановление спортсменов. Ради достижения все новых и новых рекордов внедряются новейшие научные разработки: костюмы и спортивный инвентарь изготавливаются из сверхпрочных и сверхлегких материалов, над планированием инновационных систем тренировки и особого питания работают ученые, для спортсменов выпускают эксклюзивные медицинские препараты. Наконец, спортсмены все чаще используют допинг, то есть специальные медицинские препараты, повышающие силу и выносливость.

Эти и многие другие вопросы, связанные с активным внедрением новейших технологий в индустрию спорта, способствовали несколько скептическому взгляду некоторых социологов на развитие современного спорта. Например, К. Леш [2006] рассматривает спорт как способ, позволяющий удовлетворить потребности, связанные с уровнем индустриально-технического развития. По его мнению, в условиях рынка спорт функционирует как рыночный товар, продукт потребления, средство, создающее рекламный потенциал для различных сфер общественной жизни. Ученый считает, что наблюдаемая сейчас деградация современного спорта - противоречивый, сложный и многосторонний процесс, связанный с трансформацией массовой культуры. Одним из основных результатов преобразования спорта в элемент такой культуры следует считать его тривилизацию. Спортивное соревнование разрушается под влиянием окружающих его условий и дегенерируют в зрелище. Под влиянием властной элиты усложняются политические функции спорта. Развитие зрелищного спорта до его нынешнего уровня происходит в одно и то же время с расцветом массовой культуры. Вместе с деградацией, разрушением ценностей современного спорта происходят качественные перестройки духовной жизни и нравственной морали зрителей. Коммерциализация спорта подчинила удовольствие спортсмена удовлетворению зрителя и довела последнего до уровня «вегетативной пассивности». 
По мнению К. Лэша [2006], наблюдаемые явления порождены экономическим устройством современного индустриального общества и связаны с существующим способом производства. Поскольку спорт в значительной степени представляет наиболее существенные компоненты существующей культуры, то он не только порождает и решает определенные специфические проблемы, присущие только этой подсистеме общества, но и выступает индикатором многих социальных проблем, порождаемых другими его составляющими.

\section{Развитие спорта как социально-зрелищной сферы}

Заметное место при анализе социального аспекта развития спорта занимают работы, в которых рассматриваются детерминанты становления и функционирования его как зрелища [Козлова, 2005; Сараф, 1997; Эдельман, 2008]. Ученые отмечают, что зрелищный спорт играл значительную роль на протяжении всей истории современной цивилизации и в первобытном обществе, и в античности, и в средневековье - и был связан с народными обрядами, обычаями и мифологическими представлениями. По мнению В.С. Козловой, «с распадом мифологического мышления изменились и подходы к праздникам-ритуалам, которые начали терять свое сакральное значения как школа гражданственности относительно определенных ценностей социума, а потому уже в эпоху поздней античности спортсмены начинают покупать победу, бороться за деньги, выставляя себя на продажу» [Козлова, 2005, с. 67]. Меняется отношение к тем, кто участвует в соревнованиях, а также терминология: на смену гордому званию «аскет» после разоблачения одного из них на подкупе соперника приходит термин «атлет» как обозначение того, кто выступает за вознаграждение. Доминирующим становится дух зрелищности и уже не сакральность, а зрелище становится сущностью таких игр. Именно тогда появляется своего рода рампа, которая отделяет арену (место, где проходит действо) и трибуны (место, где находится зритель) как намек на начало распада участников ритуальной целостности на производителя и потребителя зрелища.

В современных условиях профессионально-зрелищный спорт приобретает «статус социального ориентира, становится своего рода моделью выполнения собственного потенциала при успешном использования возможностей, предоставляемых социумом» [Козлова, 2005, с. 198]. Согласно законам шоу-бизнеса, спорт стремится максимально расширить свою потенциальную аудиторию, диверсифицировать свою структуру, находя все новые и новые виды соревнований.

\section{Заключение}

Современные формы существования спортивных практик являются следствием их исторической эволюции, развитие этих форм неразрывно связано с трансформацией социально-экономических отношений, складывающихся на том или ином этапе исторического развития общества. Появление в социальной среде новых форм спортивных практик обусловлено формированием специфических общественно значимых потребностей.

В научной литературе рассматриваются различные направления генезиса спорта: социально-экономическое, религиозное, игровое, культурное, образовательное, технологическое. Заметное место при анализе социального аспекта развития спорта занимают работы, в которых рассматриваются детерминанты его становления и функционирования как зрелища.

Сегодня спорт находится под влиянием глобализационных процессов, которые, с одной стороны, способствуя распространению спортивной информации, унификации технологий организации и проведения соревнований, оптимизации взаимодействия международных спортивных организаций с национальными олимпийскими комитетами и федерациями по видам спорта, многократно усилили статус спорта как общемирового явления, 
демонстрирующего общую направленность и динамику процессов глобализации. С другой стороны, в условиях глобализации происходит трансформация ценностей традиционного спорта, что приводит к качественной перестройке не только всех его составляющих, но имеет отношение также к морали, духовной жизни не только спортсменов, но и в большей степени зрителей.

\section{Список литературы}

1. Бурдье П. 1994. Программа для социологии спорта. В кн.: Бурдье П. Начала. Москва, Socio-Logos: 257-275.

2. Быховская И., Мильштейн О. 2017. Советская социология спорта: старт и... еще раз старт (субъективные заметки с претензией на объективность). Социологическое обозрение, 16 (2): 284-319. DOI: 10.17323/1728-192X-2017-2-284-319

3. Вебер М. 1990. Протестантская этика и дух капитализма. В кн. Вебер М. Избранные произведения. Москва, Прогресс: 61-135.

4. Козлова В.С. 2005. Спорт как социально-зрелищная сфера. Минск, ФУАинформ, 334 с.

5. Кун Л. 1982. Всеобщая история физической культуры. Москва, Радуга, 400 с.

6. Лукащук В.И. 2011а. Тенденции развития спорта в условиях рыночных преобразований. Изд. LAP Lambert Academic Publishimg GmbH \& Co. KG, 218 c.

7. Лукащук В.И. 2020. Социология спорта: обзор традиционных зарубежных социологических парадигм и теорий. Вестник Московского университета. Серия 18. Социология и политология, 26(2): 49-69. DOI: 10.24290/1029-3736-2020-26-2-49-69

8. Лэш К. 2006. Вырождение спорта. Логос, 3 (54): 23-40.

9. Люшен Г. 1974. К структурному анализу в спорте. В кн.: Всемирный научный конгресс «Спорт в современном обществе»: сб. научных материалов. Москва, ФиС: 25-28.

10. Ортега-и-Гассет Х. 1991. Эстетика. Философия культуры. Москва, Искусство, 592 с.

11. Романовский Н. В. 2019. Теоретическое и эмпирическое знание в социологии: современные вызовы и перспективы взаимодействия (XX Харчевские чтения). Социологические исследования, 3: 150-152. DOI: 10.31857/S013216250004288-9

12. Сараф М. Я. 1997. Спорт в культуре XX века: (Становление и тенденции развития). Теория и практика физической культуры, 7: 5-12.

13. Синютин М., Тевари С., Марки В., Нонгого П. 2016. Всемирный конгресс социологии спорта «Спорт, глобальное развитие и социальные изменения». Журнал социологии и социальной антропологии, 19-3 (86): 203-206.

14. Сироткина И. 2017. Национальные модели физического воспитания и сокольская гимнастика в России. Социологическое обозрение, 16(2): 320-339. DOI: 10.17323/1728-192X-20172-320-339

15. Столяров В.И. 2005. Социология физической культуры и спорта. Москва, Физическая культура, 400 с.

16. Хейзинга Й. 1997. Homo ludens: Статьи по истории культуры. Москва, Прогресс, 414 с.

17. Эдельман Р. Бондаренко С., Кильдюшов О. 2017. Спорт помогает ответить на фундаментальные вопросы. Интервью с Робертом Эдельманом. Социологическое обозрение, 16 (2): 275-283. DOI: 10.17323/1728-192X-2017-2-275-283

18. Эдельман Р. 2008. Серьезная забава. История зрелищного спорта в СССР. Москва, Советский спорт; АИРО-XXI, 400 с.

19. Элиас Н. 2006. Генезис спорта как социологическая проблема. Логос, 3: 41-62.

20. Лукащук B.I. 2011b. Індустрія спорту: історія та сучасність. Харків, ХНУ імені B.Н. Каразіна, 480 c.

21. Alpert R. 2015. Religion and Sports: An Introduction and Case Studies. New York, Columbia University Press, $224 \mathrm{p}$.

22. Belsky G. 2016. On the Origins of Sports: The Early History and Original Rules of Everybody's Favorite Games. New York, Artisan, 256 p.

23. Craig P. 2016. Sport Sociology (Active Learning in Sport Series). London, Sage Publications Ltd., $382 \mathrm{p}$.

24. Goldblatt D. 2016. The Games: A Global History of the Olympics. New York, W.W. Norton \& Company, $528 \mathrm{p}$. 
25. Grano D.A. 2017. The Eternal Present of Sport: Rethinking Sport and Religion Kindle. Philadelphia, Temple University Press, 284 p.

26. Grupe O. 2000. Schorndorf: Hofmann, 312 p.

27. Jeu B. Analyse du sport Français. 1992. Paris: Presses Universitaires de France, 192 p.

28. Kretchmar R.S., Dyreson M., Llewellyn M., Gleaves J. 2017. History and Philosophy of Sport and Physical Activity. Champaign, Human Kinetics, 352 p.

29. Kyle D.G. 2014. Sport and Spectacle in the Ancient World. New York, Wiley-Blackwell, 368 p.

30. Schmidt S.L. 2020. 21st Century Sports: How Technologies Will Change Sports in the Digital Age (Future of Business and Finance). Dordrecht: Springer, 442 p.

31. Schwartz D.A. 2021. Modern Sports around the World: History, Geography, and Sociology. Santa Barbara, ABC-CLIO, 410 p.

\section{References}

1. Bourdieu P. 1994. Programma dlja sociologii sporta [Program for Sociology of Sports]. In: Bourdieu P. Nachala [Choses Dites]. Moscow, Socio-Logos: 257-275.

2. Bykhovskaya I., Milstein O. 2017. The Soviet Sociology of Sport: Start and... Start Once Again (Subjective Notes with a Claim to Objectivity). Russian Sociological Review, 16 (2): 284-319. DOI: 10.17323/1728-192X-2017-2-284-319 (in Russian).

3. Weber M. 1990. Protestantskaja jetika i duh kapitalizma [The Protestant Ethic and the Spirit of Capitalism]. In: Izbrannye proizvedeniya [Selected Works]. Moscow, Publ. Progress: 61-135.

4. Kozlova B. C. 2005. Sport kak social'no-zrelishhnaja sfera [Sport as a social and entertainment sphere]. Minsk, Publ. FUAinform, 334 p. (in Russian).

5. Kun L. 1982. Vseobshhaja istorija fizicheskoj kul'tury i sporta [General History of Physical Culture and Sports]. Moscow, Publ. Raduga, 400 p.

6. Lukashchuk B. 2011a. Tendencii razvitija sporta v uslovijah rynochnyh preobrazovanij: monografija [Tendencies of Development of Sports in the Conditions of Market Transformations: monograph]. LAP LAMBERT Academic Publishimg GmbH \& Co. KG, 218 p.

7. Lukashchuk V.I. 2020. Sociology of Sport: a Review of Traditional Foreign Paradigms and Theories. Moscow State University Bulletin. Series 18. Sociology and Political Science, 26 (2): 49-69. DOI: 10.24290/1029-3736-2020-26-2-49-69 (In Russian).

8. Lasch C. 2006. Vyrozhdenie sporta [The degeneration of sport]. Logos, 3 (54): 23-40.

9. Lushen G. 1974. K strukturnomu analizu v sporte [On structural analysis in sports]. In: Vsemirnyj nauchnyj kongress «Sport v sovremennom obshhestve»: Sb. nauchnyh materialov [World Scientific Congress «Sport in Modern society»: Collection of scientific materials]. Moscow, Publ. FiS: 25-28.

10. Ortega y Gasset J. 1991. Jestetika. Filosofija kul'tury [Aesthetics. Philosophy of Culture]. Moscow, Publ. Iskusstvo, $592 \mathrm{p}$.

11. Romanovskiy N.V. 2019. Theoretical and Empirical Knowledge in Sociology: Recent Challenges and Prospects for Interaction (XX Kharchev's Readings). Sotsiologicheskie Issledovaniia, 3: 150-152. DOI: 10.31857/S013216250004288-9 (In Russian).

12. Saraf M. Ja. 1997. Sport v kul'ture XX veka: (Stanovlenie i tendencii razvitija) [Sport in the Culture of the Twentieth Century: (Formation and Development Trends)]. Teorija i praktika fizicheskoj kul'tury, 7: 5-12.

13. Sinyutin M., Tewari S., Marki V., Nonongo P. 2016. Vsemirnyj kongress sociologii sporta «Sport, global'noe razvitie i social'nye izmenenija» [World Congress of Sociology of Sport «Sport, Global Development, and Social Change»]. Journal of Sociology and Social Anthropology, 19-3 (86): 203-206.

14. Sirotkina I. 2017. Nacional'nye modeli fizicheskogo vospitanija i sokol'skaja gimnastika v Rossii [National Models of Physical Education and the Sokol Gymnastics in Russia]. Russian Sociological Review: 16(2): 320-339. DOI: 10.17323/1728-192X-2017-2-320-339 (In Russian).

15. Stolyarov V. I. 2005. Sociologija fizicheskoj kul'tury i sporta [Sociology of Physical Culture and Sports]. Moscow, Publ. Physical Culture, 400 p. (In Russian).

16. Huizinga J. 1997. Homo ludens: Stat'i po istorii kul'tury [Homo Ludens: the Study of the Play Element in Culture]. Moscow, Publ. Progress, 414 p. 
17. Edelman R., Bondarenko S., Kildyushov O. 2017. Sport Helps to Answer Fundamental Questions. Interview with Robert Edelman. Russian Sociological Review, 2: 275-283. DOI: 10.17323/1728-192X-2017-2-275-283 (In Russian).

18. Edelman R. 2008. Ser'eznaja zabava. Istorija zrelishhnogo sporta v SSSR [Serious Fun. History of Spectator sport in the USSR]. Moscow, Publ. Sovetskij sport; AIRO-XXI, 400 p.

19. Elias N. 2006. Genezis sporta kak sociologicheskaja problema [The Genesis of Sport as a Sociological Problem]. Logos, 3 (54): 41-62.

20. Lukashchuk V. I. 2011b. Industrija sportu: istorija ta suchasnist'. Monografija [Sport Industry: History and Modernity. Monography]. Kharkiv, Publ. KhNU imeni V.N. Karazina, 480 p. (In Ukraine).

21. Alpert R. 2015. Religion and Sports: An Introduction and Case Studies. New York, Columbia University Press, $224 \mathrm{p}$.

22. Belsky G. 2016. On the Origins of Sports: The Early History and Original Rules of Everybody's Favorite Games. New York, Artisan, 256 p.

23. Craig P. 2016. Sport Sociology (Active Learning in Sport Series). London, Sage Publications Ltd., $382 \mathrm{p}$.

24. Goldblatt D. 2016. The Games: A Global History of the Olympics. New York, W.W. Norton \& Company, $528 \mathrm{p}$.

25. Grano D.A. 2017. The Eternal Present of Sport: Rethinking Sport and Religion Kindle. Philadelphia, Temple University Press, $284 \mathrm{p}$.

26. Grupe O. 2000. Schorndorf: Hofmann, 312 p.

27. Jeu B. Analyse du sport Français. 1992. Paris: Presses Universitaires de France, 192 p.

28. Kretchmar R.S., Dyreson M., Llewellyn M., Gleaves J. 2017. History and Philosophy of Sport and Physical Activity. Champaign, Human Kinetics, 352 p.

29. Kyle D.G. 2014. Sport and Spectacle in the Ancient World. New York, Wiley-Blackwell, 368 p.

30. Schmidt S.L. 2020. 21st Century Sports: How Technologies Will Change Sports in the Digital Age (Future of Business and Finance). Dordrecht: Springer, 442 p.

31. Schwartz D.A. 2021. Modern Sports around the World: History, Geography, and Sociology. Santa Barbara, ABC-CLIO, $410 \mathrm{p}$.

Конфликт интересов: о потенциальном конфликте интересов не сообщалось. Conflict of interest: no potential conflict of interest related to this article was reported.

\section{ИНФОРМАЦИЯ ОБ АВТОРАХ}

Лукащук Виталий Игоревич, доктор социологических наук, профессор кафедры государственного и корпоративного управления Академии маркетинга и социальноинформационных технологий, г. Краснодар, Россия

\section{INFORMATION ABOUT THE AUTHOR}

Vitaly I. Lukashchuk, Doctor of Sociology, Professor, Department of Public and Corporate Governance, Academy of Marketing and Social Information Technologies, Krasnodar, Russia 